\title{
Phytochemical and Antimicrobial Studies of Colloidal Silver Nanoparticles Mediated by Laportea aestuans Extract
}

\author{
Owolabi Mutolib Bankole \\ Department of Chemical Sciences, Adekunle Ajasin University, Akungba, Nigeria \\ Email address: \\ bankolemutolib@yahoo.com
}

To cite this article:

Owolabi Mutolib Bankole. Phytochemical and Antimicrobial Studies of Colloidal Silver Nanoparticles Mediated by Laportea Aestuans Extract. International Journal of Biomedical Engineering and Clinical Science. Vol. 4, No. 2, 2018, pp. 58-65.

doi: 10.11648/j.ijbecs.20180402.15

Received: May 26, 2018; Accepted: June 19, 2018; Published: July 24, 2018

\begin{abstract}
This present report describes studies on the phytochemical screening and antimicrobial activity of colloidal silver nanoparticles (AgNPs) mediated by Laportea aestuans leaf extract in aqueous solution. Herein, AgNPs were facilely synthesized using the fresh leaf extract of Laportea aestuans in water. UV-Vis absorption spectrum of as-prepared AgNPs shows surface plasmon resonance (SPR) peak at $\approx 453 \mathrm{~nm}$, suggesting successful formation of AgNPs. The X-ray diffraction pattern of the AgNPs were consistent with the Bragg's reflections of AgNPs. Transmission electron microscope revealed that the prepared AgNPs are monodisperse, slightly non-aggregated and quasi-spherical in shapes. Phytochemical screenings of the leaves of $L$. aestuans shows presence of important bio-organic molecules that are responsible for the reduction, growth and stabilization of as-prepared AgNPs in aqueous solution. Bactericidal effects of the as-prepared biosynthesized AgNPs were carried out against pathogenic Gram-negative (Pseudomonas aeruginosa and Salmonella typhi) and Gram-positive (Bacillus subtilis and Staphylococcus aureus) bacteria. Biosynthesized AgNPs showed enhanced antimicrobial activity against S. aureus (gram positive) and S. typhi (gram negative), compared to B. subtilis (gram positive) and P. aeruginosa (gram negative) at the tested concentrations. Impressive antimicrobial activity of $\mathrm{L}-\mathrm{Ag}$ against the tested pathogens could be attributed to the synergistic effects of the biomolecules in the Laportea aestuans plants and silver nanostructures.
\end{abstract}

Keywords: Silver Nanoparticles, Laportea Aestuans, Antimicrobial Activity, Phytochemical Studies, Bacteria, Pathogens

\section{Introduction}

Nanotechnology has expanded over the past few decades and its impact span over wide range of applications found in material sciences, information technology, food technology, and in nanomedicine [1-3]. The latter application has drawn much attention due to wide range of methods available for treating infectious diseases, viral infections, and antibioticresistant pathogens $[4,5]$. The products of nanotechnology otherwise referred to as nanomaterials (or nanoparticles) have remarkable and exciting properties that are significantly different from the same material in bulk, due to their shapes, tiny sizes, incredible surface area per unit mass, and quantum confinement effects at the nano scale [4-7].

Silver nanoparticles (AgNPs) are important member of noble metallic (plasmonic) nanoparticles which have been extensively studied for their remarkable antimicrobial efficacy against bacteria and viruses [8-10]. They have been used as important components in several products, which include antimicrobial sterilizer, wound dressing, soaps, toothpastes and antiseptic sprays among others [11]. Different synthetic pathways have been reported for AgNPs with structural diversity such as nanospheres, nanoflowers, nanotriangles, nanorods, etc., with each structure maintaining its distinct optical and electronic properties [12]. Popular among the methods that have been reported for the synthesis of AgNPs are physical, biological and chemical reduction methods [13]. These methods however suffer from drawbacks such as the use of toxic chemicals, laborious reaction times and expensive equipment among others. Research has been swayed towards the use of green synthetic method that utilizes plant extracts to synthesize and stabilize 
colloidal silver nanoparticles in aqueous solution [8, 14].

Inspired by the above, low cost and eco-friendly protocol is reported in this work to synthesize AgNPs using aqueous extract of Laportae aestuans leaves which act as both reducing and capping agents. Laportae aestuans, commonly called West Indian woodnettle, belongs to the family of the Urticaceae; the plant is herbaceous, and grow naturally in new cultivations and fallows. They are found throughout Nigeria, Cameroun and Garbon [15-17]. Important bioactive molecules like alkaloids, tannins, flavonoids, coumarins, saponins, phlobatannins, and terpenoids are good reducing and capping agents for the preparation of metal nanoparticles [18]. These molecules are present from moderate to large concentrations in the leaf extract of Laportae aestuans [15-17]. To the best of our knowledge, the use of Laportae aestuans for the synthesis of AgNPs has not been reported before.

In this present work, colloidal silver nanoparticles were prepared via greener method using leaf extract of Laportae aestuans as reductant and capping agent, and its application as antibacterial activity against pathogenic microorganisms; Gram positive, Bacillus subtilis and Staphylococcus aureus; and Gram negative, Pseudomonas aeruginosa and Salmonella typhi.

\section{Materials and Methods}

\subsection{Materials}

Silver nitrate $\left(\mathrm{AgNO}_{3}, \mathrm{AR}\right.$ grade) was purchased from Fluka. Antibiotics standard, levofloxacin, was purchased from Sigma Aldrich. Phytochemical and antimicrobial reagents were all $\mathrm{BDH}$ analytical grade. Double distilled water was used throughout the experiments. Lyophilized cultures of Gram positive (Bacillus subtilis and Staphylococcus aureus), Gram negative (Pseudomonas aeruginosa and Salmonella typhi) bacteria, and MuellerHinton agar media were supplied by Microbiology unit of Adekunle Ajasin University, Akungba, Nigeria.

\subsection{Method}

\subsubsection{Phytochemical Analysis of L. Aestuans (Gaud) Leaves}

Fresh leaves of L. aestuans (Gaud) were collected from Adekunle Ajasin University campus located in Akungba Akoko, Ondo State, Nigeria. The plant was identified by Dr. O. A. Obembe of Plant Science and Biotechnology Department of Adekunle Ajasin University. The well airdried leaves were macerated, and then extracted with double distilled water. The extraction process requires the leaves to be soaked in water for 72 hours, filtered using vacuum filtration, and concentrated using rotary evaporator prior to phytochemical analysis. The extract obtained was used for phytochemical screening as reported below.

Test for alkaloids (Dragendorff's test).

To $1 \mathrm{~mL}$ of plant extract, $2 \mathrm{~mL}$ of Dragendorff's reagent are added and the result was observed carefully. A prominent yellow or orange red precipitate confirms the presence of alkaloids [19].

Test for carbohydrate.

$1 \mathrm{~mL}$ of plant extract was boiled on water bath with $1 \mathrm{~mL}$ of Fehling solutions. Formation of red precipitate indicates the presence of sugar in the plant [20].

Test for glycosides.

Ammonia (10\%) and Chloroform $(3 \mathrm{~mL})$ were both added to the plant extract $(2 \mathrm{~mL})$. Formation of pink precipitate indicates the presence of glycosides [21].

Test for phytosterols (Liberdmann-Burchard's test).

The plant extract was added to solution of acetic anhydride ( $2 \mathrm{~mL}$ ), followed by slow addition of 2 drops of concentrated sulphuric acid along the sides of the test tube. Formation of bluish-green colour indicates the presence of phytosteroids and/or steroids [22].

Test for Tannins (ferric chloride test).

A few drops of neutral 5\% ferric chloride solution were added to the mixture of plant extract and $5 \mathrm{~mL}$ of distilled water. Formation of blue green color indicates the presence of tannins.

Test for Phenols (Lead acetate) test.

Extract of $L$. aestuans was dissolved into small quantity of distilled water, followed by addition of $3 \mathrm{~mL}$ of $10 \%$ acetate solution. A bulky white precipitate indicates the presence of phenols

Test for flavonoids.

Aqueous solution of the plant extract was treated with ammonium hydroxide solution. Formation of yellow fluorescence indicates the presence of flavonoids.

Test for coumarins.

Few quantity of plant extract $(1 \mathrm{~mL})$ was treated with $10 \%$ $\mathrm{NaOH}(1 \mathrm{~mL})$. Formation of yellow colour confirms the presence of coumarins.

Test for saponin.

Plant extract $(1 \mathrm{~mL})$ was treated with distilled water of about $2 \mathrm{~mL}$ and shaken for few seconds. Formation of $1 \mathrm{~cm}$ foam indicates the presence of saponin [23].

Test for phlobatannins.

Few drops of $10 \%$ ammonia solution were treated with 0.5 $\mathrm{mL}$ of the plant extract. Appearance of pink color confirms the presence of phlobatannins.

Test for cardiac glycosides.

Plant extract $(1 \mathrm{~mL})$ was treated with mixture of glacial acetic acid $(2 \mathrm{~mL})$ and few drops of 5\% ferric chloride. The resulting mixtures was unlayered by adding $1 \mathrm{~mL}$ of concentrated sulphuric acid. Presence of cardiac glycosides is confirmed by formation of brown ring at the solution interface.

Test for terpenoids.

Mixture of chloroform $(2 \mathrm{~mL})$ and concentrated sulphuric acid were added plant extract $(0.5 \mathrm{~mL})$. Presence of terpenoids is confirmed by the formation of red brown colour at the interface.

Detection of fixed oil and fat (Spots test).

Small quantity of plant extract was pressed between two filter papers. Oil stain on the paper indicates the presence of fixed oils and fats. 


\subsubsection{Biosynthesis of L. Aestuans Capped AgNPS (L-Ag), Figure 1}

$40 \mathrm{~g}$ of dried, powdered leaves of L. aestuans was added to $100 \mathrm{~mL}$ of double distilled water in a $500 \mathrm{~mL}$ conical flask. Then the solution was boiled at $50{ }^{\circ} \mathrm{C}$ for $60 \mathrm{~min}$. The supernatant was separated by filtration using Whatman filter paper $(125 \mathrm{~mm})$. The extract was stored in the refrigerator at $4{ }^{\circ} \mathrm{C}$ prior to synthesis of AgNPs.

For biosynthesis of AgNPs, $30 \mathrm{~mL}$ solution of $0.01 \mathrm{M}$ silver nitrate $\left(\mathrm{AgNO}_{3}\right)$ was prepared and magnetically stirred for $5 \mathrm{~min}$. Then $5 \mathrm{~mL}$ of the $L$. aestuans plant extract was added to the solution with continuous stirring. The resulting notable colour change from colorless solution to reddish brown indicates successful reduction of silver ions $\left(\mathrm{Ag}^{+}\right)$to silver nanoparticles $\left(\mathrm{Ag}^{\mathrm{O}}\right)$, Figure 1. The biosynthesized AgNPs was washed with abs. EtOH, dried at room temperature for $24 \mathrm{~h}$. Purified AgNPs were dispersed in aqueous solution for further characterizations.

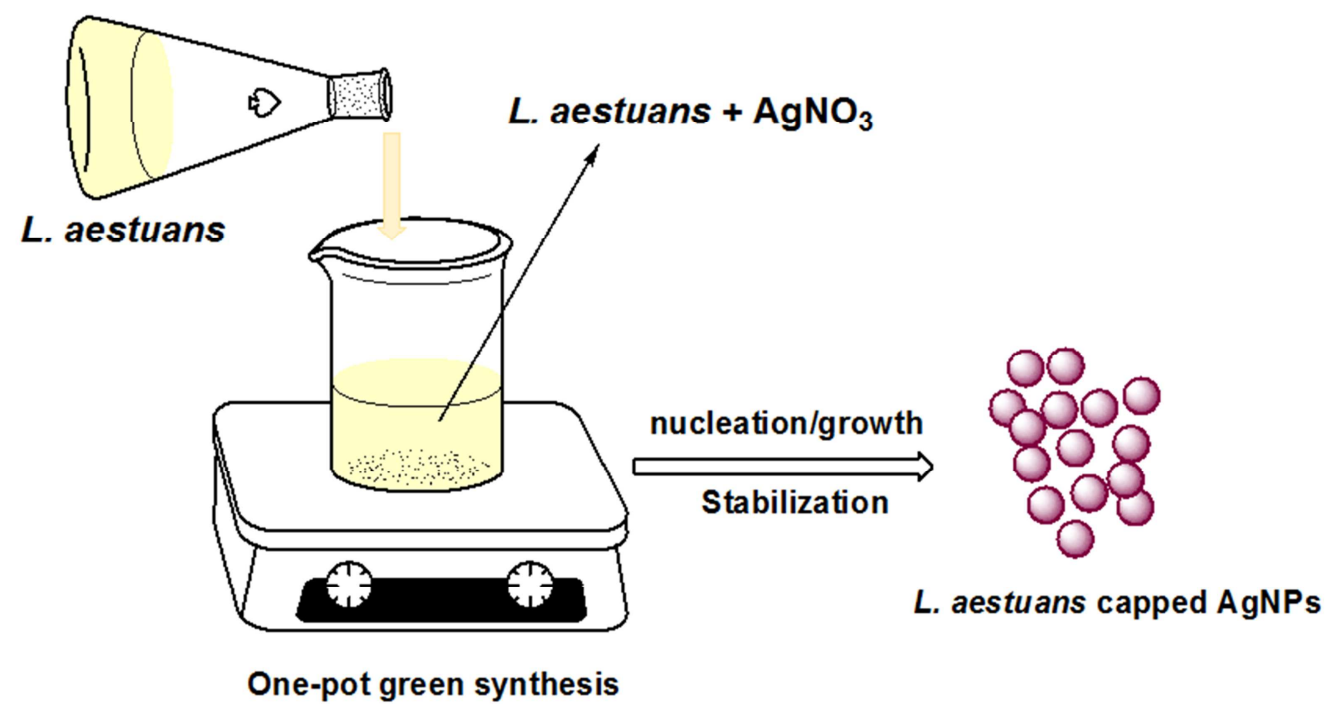

Figure 1. Typical one-pot synthetic pathway for the preparation of biosynthesized AgNPS (L-Ag).

\subsection{Characterization of Biosynthesized AgNPs (L-Ag)}

The plant mediated reduction of silver ions was monitored by recording the spectra between 200 to $800 \mathrm{~nm}$ on a double beam (Shimadzu, UV-2550) UV-Vis spectrophotometer. The morphology, size and shapes of the as-prepared AgNPs was visualized using the $80 \mathrm{k}$ Vultra-high-resolution transmission electron microscope, TEM, (Zeiss-EM10C). The TEM imaging was visualized by dropping the solid sample on carbon-coated copper grid. The morphological and crystallinity of the nanoparticles were analyzed using X-ray diffraction spectroscopy (Philips pan analytical). Phases of the synthesized nanoparticles were analyzed using $\mathrm{X}$ pert high score software.

\subsection{Antimicrobial Activity of Biosynthesized AgNPS}

\subsubsection{Standardization of Test Pathogenic Bacteria}

The test organisms which including gram positive, Bacillus subtilis and Staphylococcus aureus, and gram negative, Pseudomonas aeruginosa and Salmonella typhi, were isolated and a colony was emulsified in normal saline until its turbidity equals $0.5 \mathrm{McF}$ arland standards which approximately equal to $1 \times 10^{8} \mathrm{cf \mu} / \mathrm{mL}$ organisms present.

\subsubsection{Preparation of the Standard (Levofloxacin) Solution}

Standard solution of levofloxacin drug was prepared by adding $0.1 \mathrm{~g}$ of levofloxacin into $10 \mathrm{~mL}$ of sterile water to give $10 \mu \mathrm{g} / \mathrm{mL}$. Different concentrations of the standard drugs for antimicrobial studies were prepared as follows:
$100 \mu \mathrm{g} / \mathrm{mL}: 0.1 \mathrm{~mL}$ of $10 \mathrm{mg} / \mathrm{mL}$ (standard) $+9.9 \mathrm{~mL}$ of sterile water.

$50 \mu \mathrm{g} / \mathrm{mL}: 5 \mathrm{~mL}$ of $100 \mu \mathrm{g} / \mathrm{mL}+5 \mathrm{~mL}$ of sterile water.

$25 \mu \mathrm{g} / \mathrm{mL}: 5 \mathrm{~mL}$ of $50 \mu \mathrm{g} / \mathrm{mL}+5 \mathrm{~mL}$ of sterile water.

\subsubsection{Preparation of Silver Nanoparticles for Antimicrobial Analysis}

Colloidal silver nanoparticles with concentration of 30 $\mathrm{ppm}$ or $30 \mu \mathrm{g} / \mathrm{mL}$ was prepared and used for the antimicrobial analysis. Serial dilution method was used to prepare lower concentrations $(1.825,3.25,7.5,15,30$ and 50 $\mu \mathrm{g} / \mathrm{mL}$ ).

\subsubsection{Antimicrobial Assay (Minimum Inhibition Concentration, $\mathrm{MIC}$ )}

Antimicrobial screenings of aqueous silver nitrate, biosynthesized silver nanoparticles (L-Ag), L. aestuans extract, and standard antibiotics, levofloxacin, were carried out against test organisms, using well- and disk-diffusion methods. Briefly, $1 \mathrm{~mL}$ of the test organisms were dispensed aseptically into different sterile petri-dishes labelled with name of each organism. $25 \mathrm{~mL}$ of prepared (molten agar) of Mueller-Hinton Agar (MHA) was then poured into the each dish containing the $1 \mathrm{~mL}$ of standardized organisms, and thoroughly swirled for proper mixture (homogenization). The media were allowed to solidify. A sterile cork borer was used to create wells in the solidified media and $0.2 \mu \mathrm{L}$ of each sample, L-Ag, plant extract, $\mathrm{AgNO}_{3}$ or levofloxacin, was then dispersed into the wells aseptically. All the petri plates were incubated at $35^{\circ} \mathrm{C}$ for $24 \mathrm{~h}$. The diameter of inhibition 
zone in mm was measured to determine the minimum inhibitory concentration (MIC) and/or minimum bactericidal concentration $(\mathrm{MBC})$ of the tested samples on the organisms. The measurements were carried out in triplicate for accuracy [14].

\section{Result and Discussion}

\subsection{Synthesis and Characterizations}

The plant-mediated synthesis of silver nanoparticles using aqueous extract of $L$. aestuans at room temperature was completed within few minutes. In a typical synthesis, the colour of $\mathrm{AgNO}_{3}$ and L. aestuans mixture changed from light yellow to reddish brown, due to the conversion of mono oxidation state of $\mathrm{Ag}$ to its zero-valent state $\left(\mathrm{Ag}^{\circ}\right)$, Figure 2 . The growth and stabilization of biosynthesized AgNPs in solution was attributed to the presence of bioactive molecules present in the leaves of $L$. aestuans, hence $L$. aestuans acts as a reducing and capping agent to improve the stability, dispersibility and activity of AgNPs in solution. Similar observations have been reported for bio-reduction of metal salts in the presence of plant extracts [24-26]. The asprepared AgNPs were purified, lyophilized and characterized by UV-Vis, XRD, and TEM.

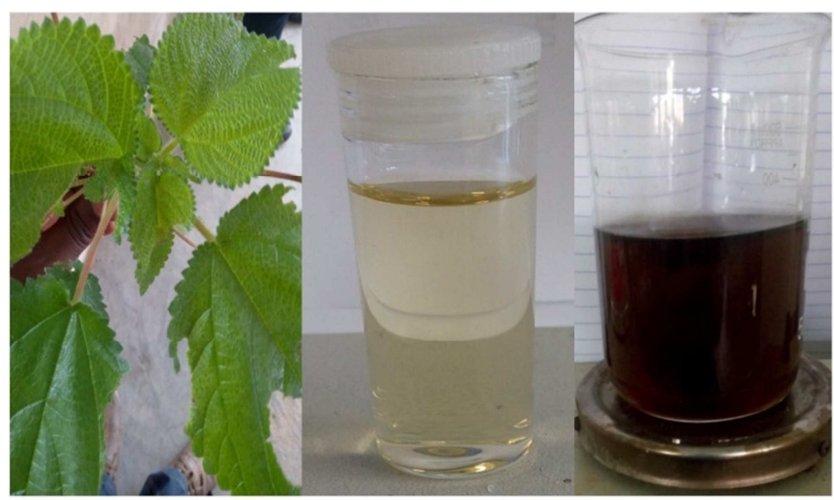

Figure 2. Visual observation showing L. aestuans leaves, plant extract of $L$. aestuans and colour of biosynthesis of AgNPs after reaction time of $5 \mathrm{~min}$.

Normalized UV-Vis spectra of L. aestuans extract and biosynthesized silver nanoparticles (L-Ag) in water are presented in Figure 3. Absorption of spectrum of L. aestuans extract revealed bands at around 289 and $320 \mathrm{~nm}$, corresponding to the magnitude of resonance delocalization ( $\pi \rightarrow \pi$ conjugative characters) in the biomolecules in the plant extract [27]. Previous report has shown that absorption band around 280 and $330 \mathrm{~nm}$ could be due to the presence of polyphenols (tannins) and flavonoids, respectively [27]. Absorption spectrum of biosynthesized AgNPs has absorption maxima in the range of $400-500 \mathrm{~nm}$, and peaked at $453 \mathrm{~nm}$ due to the formation of surface plasmon resonance (SPR). The intense absorption peak at $\approx 453 \mathrm{~nm}$ indicates the successful formation of silver nanoparticles. Absence of the absorption peak at $453 \mathrm{~nm}$ in the spectrum of L. aestuans shows that the observed SPR in L-Ag is due to the successful formation of $\mathrm{Ag}^{\circ}$ in solution.

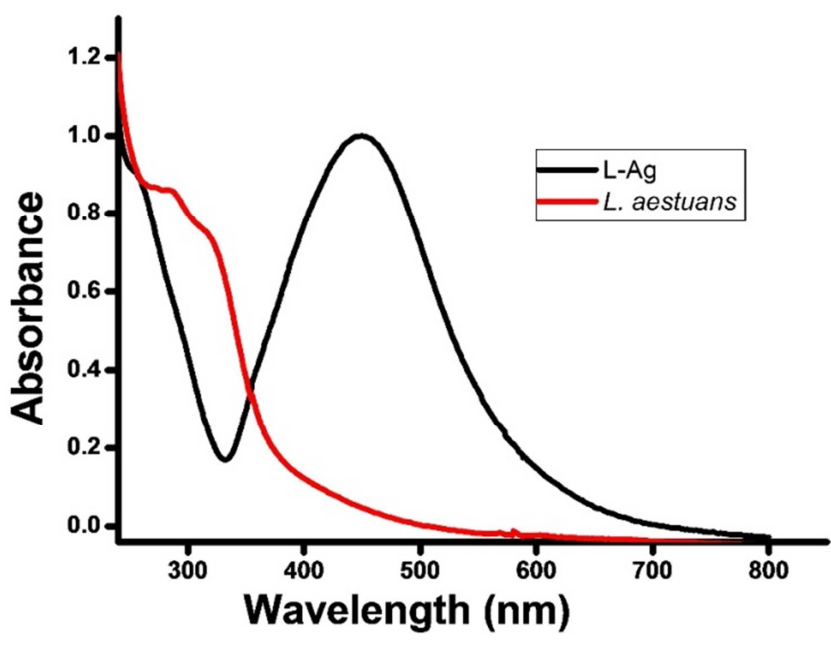

Figure 3. UV-Vis spectra of Laportea aestuans and AgNPs in water.

Transmission electron microscopy (TEM) technique was used to visualize the morphology of the biosynthesized AgNPs. Figure 4 shows monodisperse, slightly nonaggregated and quasi-spherical nanoparticles. The dispersed nanoparticles are capped with organic molecules contained in the $L$. aestuans evidenced from the black thin layer coverage around the nanoparticles. The biosynthesized nanoparticles have an estimated particle size of $25 \pm 1.4 \mathrm{~nm}$, evidenced from the broader absorption peak as observed in UV-Vis spectrum of L-Ag, Figure 3.

The X-ray diffraction of the biosynthesized AgNPs is shown in Figure 5. The synthesized AgNPs were crystalline in nature with five distinct crystalline diffraction peaks. The Bragg's reflections of silver nanoparticles were observed at $2 \theta=38.09^{\circ}(111), 46.1^{\circ}(200), 64.3^{\circ}(220), 78.2^{\circ}(311)$ and $82.1^{\circ}(222)$. Broadening of XRD patterns is attributed to particle defects occasioned by the presence of organic phases on the surface of AgNPs

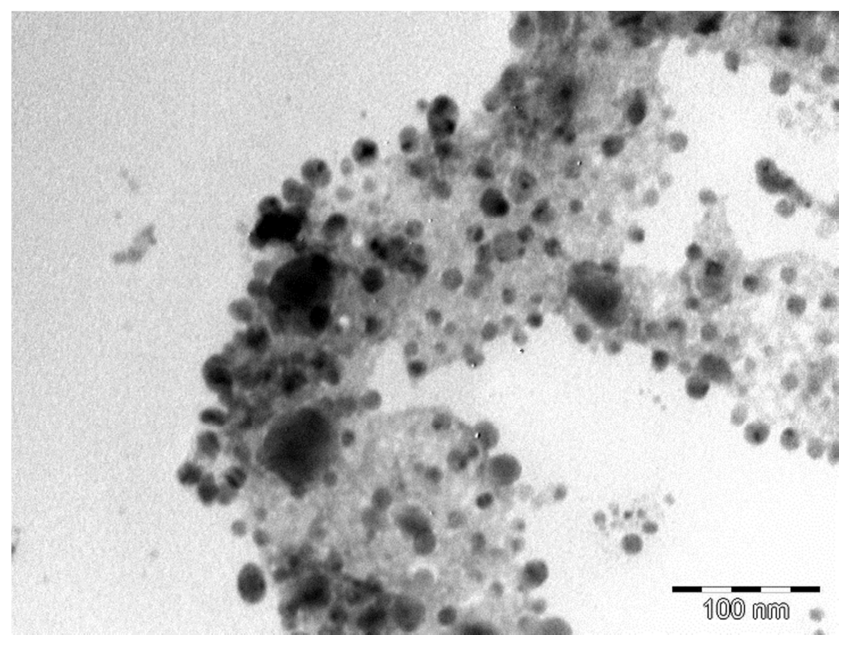

Figure 4. Transmission electron microscopy (TEM) image of L. aestuans capped AgNPs. 


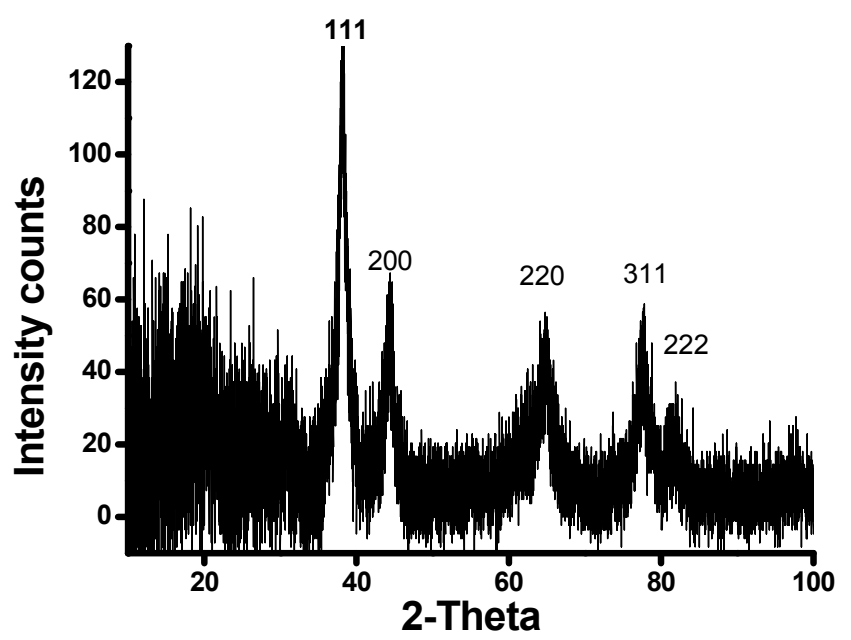

Figure 5. X-ray diffraction patterns of biosynthesized silver nanoparticles.

\subsection{Phytochemical Analysis}

Bio-organic compositions of L. aestuans leaves responsible for the reduction, growth and stabilization of AgNPs in solution, were qualitatively verified in aqueous solution. It could be observed that important biomolecules such as alkaloids, tannins, flavonoids, coumarins, saponins, and phlobatannins, are abundantly present in the leaves of $L$. aestuans, Table 1 . The results were in good agreements with previous study conducted on the leaves of Laportea aestuans as reported by Essiett et al [15]. Carbohydrate, terpenoids and fixed oil are present in moderate concentrations, while biomolecules like glycosides, phenols and asteroids/phytosteroids are completely absent. Similar observations were also reported in the crude methanol extract of $L$. aestuans leaves [16].

Table 1. Qualitative phytochemical analysis of Laportea aestuans.

\begin{tabular}{ll}
\hline Metabolites & L. aestuans water extract \\
\hline Alkaloids & +++ \\
Carbohydrates & ++ \\
Glycosides & - \\
Phytosteroid/steroids & $-/-$ \\
Tannins & +++ \\
Phenol & - \\
Flavonoids & +++ \\
Coumarins & +++ \\
Saponins & +++ \\
Phlobatannins & +++ \\
Cardiac glycosides & - \\
Terpenoids & ++ \\
Fixed oil & ++ \\
\hline
\end{tabular}

$+=$ Traces,$++=$ Moderately present,

$+++=$ Abundantly present,$-=$ Absent

Direct antibacterial, antivirulence, and antibiotic enhancing activities of alkaloids, flavonoids in several important drugs have been extensively studied and reported in literature $[17,28]$. Terpenoids elicit a wide range of therapeutic actions on membrane disruption and inhibition of bacterial cell or fungus, hence they have good antibacterial and antifungal activities [29, 30].

Presence of other bio-active molecules like tannins, saponins, coumarins, and phlobatannins are the basis of the therapeutic potentials exhibited by $L$. aestuans against several pathogenic microorganisms [31-37]. Also, the plurality of hydroxyl and carbonyl groups in the plant extract facilitated the reduction and stabilization of AgNPs in solution [38], this justified the use of L. aestuans as a reducing and stabilizing agent in this work.

\subsection{Bacteriostatic Studies of Biosynthesized AgNPs (L-Ag)}

Bacteriostatic effects of the biosynthesized AgNPs against four clinical isolates, B. subtilis and $S$. aureus, P. aeruginosa, and $S$. typhi, were evaluated using minimum inhibitory concentration (MIC) method. Fixed concentration of each isolate $\left(1 \times 10^{8} \mathrm{CFU} / \mathrm{mL}\right)$ was separately contacted with different concentrations of biosynthesized AgNPs (1.825, $3.25,1.75,15,30$ and $50 \mu \mathrm{g} / \mathrm{mL}$ ), and incubated for $24 \mathrm{~h}$. The results for the bacteriostatic activities of L-Ag against the studied pathogens are summarized in Table 2. Bacteriostatic activity of the as-prepared AgNPs against $S$. aureus and $S$. typhi was recorded at minimum concentration of $7.5 \mu \mathrm{g} / \mathrm{mL}$, while the minimum inhibition concentration of $15 \mu \mathrm{g} / \mathrm{mL}$ was observed for both $P$. aeruginosa and $B$. subtilis. It is noteworthy to mention that concentration of L$\mathrm{Ag}$ below $7.5 \mu \mathrm{g} / \mathrm{mL}$ is not potent enough to inhibit the growth of the tested microorganisms, indicating that the MIC of L-Ag to the pathogens ranged from 7.5 to $15 \mu \mathrm{g} / \mathrm{mL}$, Table 2. Inhibition of the bacteria growth above $7.5 \mu \mathrm{g} / \mathrm{mL}$ in the presence of L-Ag could be attributed to the simultaneous release of diffusible inhibitory chemical compounds, $\mathrm{Ag}^{\circ}$, and bio-active molecules, of the prepared L-Ag.

Table 2. Minimum Inhibitory Concentration (MIC) results on the tested organisms at different concentrations.

\begin{tabular}{lllll}
\hline \multirow{2}{*}{ Test Organisms } & $\mathbf{1 . 8 2 5}$ & $\mathbf{3 . 2 5}$ & $\mathbf{7 . 5}$ & $\mathbf{1 5}$ \\
& $\mu \mathbf{g} / \mathbf{m L}$ & $\mu \mathbf{g} / \mathbf{m L}$ & $\mu \mathbf{g} / \mathbf{m L}$ & $\mu \mathbf{g} / \mathbf{m L}$ \\
\hline Staphylococcus aureus & + & + & - & - \\
Bacillus subtilis & + & + & + & - \\
Salmonella typhi & + & + & - & - \\
Pseudomonas aeruginosa & + & + & + & - \\
\hline
\end{tabular}

\subsection{Antibacterial Studies of $L-A g$}

Antibacterial screenings against tested pathogenic organisms were also carried out using samples which include aqueous solution of $\mathrm{AgNO}_{3}$, L. aestuans extract, and biosynthesized L-Ag. Water and antibiotic standard, levofloxacin, are used as negative and positive controls, respectively. The results of the antibacterial screenings are summarized in Tables 3 and 4. Water had no antibacterial activity on all the tested organisms as expected. Aqueous extract of $L$. aestuans had maximum zone of $9.57 \pm 0.1 \mathrm{~mm}$ inhibition of against $S$. aureus, followed by $S$. typhi with zone of inhibition of $8.42 \pm 0.3 \mathrm{~mm}, P$. aeruginosa, however has the minimum zone of inhibition of $3.12 \pm 0.3 \mathrm{~mm}$ among the tested organisms. The measured inhibition zone of diameters for the tested organisms were observed to increased linearly as the concentration of L-Ag was increased from 15 to 50 $\mu \mathrm{g} / \mathrm{L}$. The results suggest that more diffusible inhibitory 
lethargic $\mathrm{Ag}^{\mathrm{o}}$ from biosynthesized silver NPs were released at higher concentrations, hence silver nanoparticles mediated by extract of $L$. eastuans displayed impressive antimicrobial activity against both gram negative and gram positive bacteria. Similar trends were also observed when antibiotic standard, lexoflaxin, was used as positive control, Table 4. At $50 \mu \mathrm{g} / \mathrm{L}$ dosage of L-Ag, highest zone inhibition of $\approx 25 \mathrm{~mm}$, $\approx 19 \mathrm{~mm}, \approx 24 \mathrm{~mm}$, and $\approx 11 \mathrm{~mm}$ were observed for $S$. aureus, B. subtilis, S. typhi, and P. aeruginosa, respectively, suggesting that L-Ag showed better antibacterial activity against S. aureus (gram positive) and $S$. typhi (gram negative), compared to $B$. subtilis (gram positive) and $P$. aeruginosa (gram negative). Phongtongpasuk and coworkers have also demonstrated that colloidal AgNPs mediated by dragon peel extract (DPE) have stronger antibacterial activity against $S$. aureus than $P$. aeruginosa [14]. Cases of reduction of $P$. aeruginosa sensitivity to broad-spectrum antimicrobial agents have also been reported before [39, 40]. The lowest zone of inhibition reported for $P$. aeruginosa among the tested pathogens in this work could be attributed to the formation of bacterial biofilms, which could lead to limited diffusion of L-Ag into the biofilm matrix, or due to possible adaptive bacterial response to L-Ag [41-43]. Improved bactericidal effect of L-Ag could be attributed to the synergistic effects of the biomolecule contents of $L$. eastuans and silver nanostructures. Enhanced antimicrobial activities of silver nanoparticles in the presence of plant extracts are well documented in the literature [44-47]. The standard however had strong activity on all tested organism as shown in Table 4.

Table 3. Zone of inhibition (mean $\pm S D$ ) of water, L. aestuans leaf extract, and aqueous solution of L. aestuans capped AgNPs (L-Ag) against bacterial pathogens.

\begin{tabular}{|c|c|c|c|c|c|}
\hline \multicolumn{6}{|l|}{ Zone of inhibition (mm) } \\
\hline \multirow{2}{*}{ Bacteria } & \multirow{2}{*}{ Water } & \multirow{2}{*}{ Leaf extract $(I Z \pm S D)$} & \multicolumn{3}{|l|}{ L-Ag $(\mu \mathrm{g} / \mathrm{mL})$} \\
\hline & & & $15(I Z \pm S D)$ & $30(I Z \pm S D)$ & $50(I Z \pm S D)$ \\
\hline Staphylococcus aureus & $\mathrm{NI}$ & $9.57 \pm 0.1$ & $16.17 \pm 0.4$ & $20.21 \pm 0.2$ & $25.04 \pm 0.3$ \\
\hline Bacillus subtilis & NI & $7.13 \pm 0.5$ & $10.12 \pm 0.4$ & $16.06 \pm 0.4$ & $19.13 \pm 0.4$ \\
\hline Salmonella typhi & NI & $8.42 \pm 0.3$ & $13.14 \pm 0.4$ & $18.11 \pm 0.4$ & $24.21 \pm 0.4$ \\
\hline Pseudomonas aeruginosa & NI & $3.12 \pm 0.3$ & $5.42 \pm 0.3$ & $6.02 \pm 0.4$ & $11.13 \pm 0.4$ \\
\hline
\end{tabular}

$\mathrm{NI}=$ No inhibition; IZ = inhibition zones in diameter $(\mathrm{mm}) ; \mathrm{SD}=$ standard deviation; $\mathrm{L}-\mathrm{Ag}=$ L.aestuans capped AgNPs.

Table 4. Zone of inhibition (mean \pm SD) of antibiotic drug, lexofloxavin, against bacterial pathogens.

\begin{tabular}{llll}
\hline Zone of inhibition $(\mathbf{m m})$ & & & \\
\hline \multirow{2}{*}{ Bacteria } & Levofloxacin $(\boldsymbol{\mu g} / \mathbf{L})$ & $\mathbf{3 0}(\mathbf{I Z} \pm \mathbf{S D})$ \\
\cline { 2 - 4 } & $\mathbf{1 5}(\mathbf{I Z} \pm \mathbf{~ S D})$ & $29.21 \pm 0.2$ & $\mathbf{5 0}(\mathbf{I Z} \pm \mathbf{S D})$ \\
\hline Staphylococcus aureus & $23.57 \pm 0.4$ & $31.57 \pm 0.4$ & $34.04 \pm 0.3$ \\
Bacillus subtilis & $25.57 \pm 0.4$ & $26.57 \pm 0.4$ & $36.57 \pm 0.4$ \\
Salmonella typhi & $20.57 \pm 0.4$ & $19 . \pm 0.4$ & $23.57 \pm 0.4$ \\
Pseudomonas aeruginosa & $16.57 \pm 0.4$ & 0.4 & 23.57 \\
\hline
\end{tabular}

IZ and SD as explained above.

\section{Conclusion}

Herein, a sustainable, facile and green method was adopted to synthesize AgNPs using Laportea aestuans leaf extract which produce spherical shaped AgNPs at ambient conditions. The biomolecule contents of $L$. aestuans served as reducing or stabilizing agents for the as-prepared AgNPs. The shape, size and crystallinity of the resulting AgNPs were confirmed using techniques such as UV- vis spectroscopy, XRD and TEM. Results from UV-vis absorption spectrum of as-prepared AgNPs shows surface plasmon resonance (SPR) peak observed at $\approx 453 \mathrm{~nm}$, suggesting successful formation of AgNPs. The X-ray diffraction pattern of the AgNPs were consistent with the Bragg's reflections of AgNPs. Transmission electron microscope revealed that the prepared AgNPs are monodisperse, slightly non-aggregated and quasispherical in shapes. Important bio-organic molecules like alkaloids, tannins, flavonoids, coumarins, saponins, and phlobatannins were quantitatively verified to be abundantly present in the leaves of $L$. aestuans. Other bioactive molecules present in the leaves are carbohydrate, terpenoids and fixed oil. The presence of these molecules are responsible for the reduction, growth and stabilization of asprepared AgNPs in aqueous solution. Bactericidal effects of the as-prepared biosynthesized AgNPs were carried out on Salmonella typhi, Pseudomonas aeruginosa, Bascillus subtilis and Staphyloccocus aureus. Biosynthesized AgNPs showed enhanced antimicrobial activity against S. aureus (gram positive) and $S$. typhi (gram negative), compared to $B$. subtilis (gram positive) and $P$. aeruginosa (gram negative) at the tested concentrations. Impressive antimicrobial activity of L-Ag against the tested pathogens could be attributed to the synergistic effects of the biomolecules in the Laportea aestuans plant, and silver nanostructures.

\section{References}

[1] G. Kaur, T. Singh, A. Kumar, Nanotechnology: A review, IJEAR, 2(1), 2012, 50-53. 
[2] F. Sanchez, K. Sobilev, Nanotechnology in concrete- A review, Constr. and Build. Mater, 24(11), 2010, 2060-2071.

[3] V. D. Krishna, K. Wu, D. Su, M. C. J. Cheeran, J.-P. Wang, A Perez, Nanotechnology: Review of concepts and potential application of sensing platforms in food safety, Food Microbiol., 2018 (In Press, Corrected Proof).

[4] T. S. Hauck, S. Giri, Y. Gao, W. C. W. Chan, Nanotechnology diagnostics for infectious diseases prevalent in developing countries, Adv. Drug Deliv. Rev., 62 (4-5) 2010, 438-448.

[5] E. Torres-Sangiao, A. M. Holban, M. C. Gestal, Advanced nanobiomaterials: vaccines, diagnosis and treatment of infectious diseases, Molecules 21, 2016, 867-889.

[6] K. Thorkelsson, P. Bai, T. Xu, Self-assembly and applications of anisotropic nanomaterials: A review, Nano Today, 10 (1) 2015, 48-66.

[7] J. Jeevanandam, A. Barhoum, Y. S. Chan, A. Dufresne, M. K. Danquah, Review on nanoparticles and nanostructured materials: history, sources, toxicity and regulations, Beilstein J. Nanotechnol. 9, 2018, 1050-1074.

[8] B. Buszewski, V. Railean-Plugaru, P. Pomastowski, K. Rafinska, M. Szultka-Mlynska, P. Golinska, M. Wypij, D. Laskowski, H. Dahm, Antimicrobial activity of biosilver nanoparticles produced by a novel Streptacidiphilus durhamensis strain, J. Microbiol. Immunol. Infect, 51, 2018, 45-54.

[9] M. Bilal, T. Rasheed, H. M. N. Iqbal, H. Hu, X. Zhang, Silver nanoparticles: biosynthesis and antimicrobial potentialities, International Journal of Pharmacology, 13(7), 2017, 832-845.

[10] D. Arul, G. Balasubramani, V. Balasubramanian, T. Natarajan, P. Perumal, Antibacterial efficacy of silver nanoparticles and ethyl acetate's metabolites of the potent halophilic (marine) bacterium, Bacillus cereus A30 on multidrug resistant bacteria, Pathog. Glob. Health, 111(7), 2017, 367-382.

[11] K. Chaloupka, Y. Malam, A. M. Seifalian, Nanosilver as a new generation of nanoproduct in biomedical applications. Trends Biotechnol 28, 2010, 580-588.

[12] U. T. Khatoon, G. V. S. N. Rao, K. M. Mantravadi, Y. Oztekin, Strategies to synthesize various nanostructures of silver and their applications - a review, RSC Adv., 8, 2018, 19739-19753.

[13] S. Iravani, H. Korbekandi, S. V. Mirmohammadi, B. Zolfaghari, Synthesis of silver nanoparticles: chemical, physical and biological methods, Res. Pharm. Sci. 9(6), 2014, 385-406.

[14] S. Phongtongpasuka, S. Poadanga, N. Yongvanich, Environmental-friendly method for synthesis of silver nanoparticles from dragon fruit peel extract and their antibacterial activities, Energy Procedia 89, 2016, 239-247.

[15] U. A Essiett, N. I. Edet and D. N. Bala, Phytochemical and physicochemical analysis of the leaves of Laportea aestuans (Linn.) Chew and Laportea ovalifolia (Schumach.) Chew (male and female), Asian Journal of Plant Science and Research, 1 (2), 2011, 35.

[16] G. K. Oloyede, O. E. Ayanbadejo, Phytochemical, toxicity, antimicrobial and antioxidant screening of extracts obtained from Laportea aestuans (Gaud), J. Med. Sci. 14 (2), 2014, 5159.
[17] U. A. Essiett, D. N. Bala, J. A. Agbakahi, Pharmacognostic studies of the leaves and stem of Diodia scandens SW in Nigeria, Archives of Applied Science Research, 2(5), 2010, 184-198.

[18] S. Ahmed, M. Ahmad, B. L. Swami, S. Ikram, A review on plants extract mediated synthesis of silver nanoparticles for antimicrobial applications: A green expertise, J. Adv. Res. 7, 2016, 17-28.

[19] D. Waldi, Spray Reagents for Thin-Layer, Chromatography. In: Egon Stahl (Ed.). Thin Layer Chromatography- A Laboratory Handbook. Acadmic press Inc., Publishers, New York, U. S. A. (1965).

[20] S. Ramkrishnan, R. Rajan, Text book of medical Biochemistry, Orient Longman, New Delhi, India (1994).

[21] W. C. Evans, Trease and Evans Pharmacology, 14th edn. Harcourt Brace and company. Asia. Pvt. Ltd., Singapore (1997).

[22] I. L. Finar, Stereo Chemistry and the Chemistry of Natural products 2, Longman, Singapur (1986).

[23] C. K. Kokate, Practical Pharmacognosy. 4th edn., Vallabh Prakashan Publication, New Delhi, India (1999).

[24] J. R. Nakkala, R. Mata, G. A. Kumar, S. S. Rani, Biological activities of green silver nanoparticles synthesized with Acorous calamus rhizome extract. Eur J Med Chem 85, 2014, 784-94.

[25] J. R. Nakkala, R. Mata, G. A. Kumar, S. S. Rani, Green synthesis and characterization of silver nanoparticles using Boerhaavia diffusa plant extract and their antibacterial activity. Indus Crop Prod 52, 2014, 562-6.

[26] Q. Suna, X. Cai, J. Li, M. Zheng, Z. Chenb, C. P. Yu, Green synthesis of silver nanoparticles using tea leaf extract and evaluation of their stability and antibacterial activity. Colloid Surf A: Physicochem Eng Aspects 444, 2014, 226-31.

[27] F. Bunghez, C. Socaciu, F. Zagrean, R. M. Pop, F. Ranga, F. Romanciuc, Characterisation of an aromatic plant-based formula using UV-Vis Spectroscopy, LC-ESI (+)QTOF-MS and HPLC-DAD Analysis Bulletin UASVM Food Science and Technology 70(1), 2013, 16-24.

[28] T. P. Tim Cushnie, B. Cushnie, A. J. Lamb, Alkaloids: An overview of their antibacterial, antibiotic enhancing and antivirulence activities, Int. J. Antimicrob. Agents, 44(5), 2014, 377-386.

[29] H. Zengin, A. H. Baysal, Antibacterial and antioxidant activity of essential oil terpenes against pathogenic and spoilageforming bacteria and cell structure-activity relationships evaluated by SEM microscopy, Molecules 19, 2014, 1777317798.

[30] S. A. Zacchino, E. Butassi, M. D. Liberto, M. Raimondi, A. Postigo, M. Sortino, Plant phenolics and terpenoids as adjuvants of antibacterial and antifungal drugs, Phytomedicine, 15(37), 2017, 27-48.

[31] L. M. Redondo, P. A. Chacana, J. E. Dominguez, M. E. F. Miyakawa, Perspectives in the use of tannins as alternative to antimicrobial growth promoter factors in poultry, Front Microbiol, 5, 2014, 118-124.

[32] F. Mert-TŸrk, Saponins versus plant fungal pathogens, J Cell Biol Mol Sci., 5, 2006, 13-17. 
[33] J. J. Coleman, I. Okoli, G. P. Tegos, E. B. Holson, F. F. Wagner, M. R. Hamblin, E. M. Characterization of plantderived saponin natural products against Candida albicans, ACS Chem Biol. 5(3), 2010, 321-332.

[34] A. F. Ade-Ajayi, C. Hammuel, C. Ezeayanaso, E. E. Ogabiela, U. U. Udiba, B. Anyim, O. Olabanji, Preliminary phytochemical and antimicrobial screening of Agave sisalana Perrine juice (waste), J. Environ. Chem. Ecotoxicol, 3(7), 2011, 180-183.

[35] P. O. Ukoha, E. A. C. Cemaluk, O. L. Nnamdi, E. P. Madus, Tannins and other phytochemical of the Samanaea saman pods and their antimicrobial activities, Afr. J. Pure Appl. Chem., 5(8), 2011, 237-244.

[36] N. L. Brooker, Y. Kuzimichev, J. Laas, R. Pavlis, Evaluation of coumarin derivatives as anti-fungal agents against soilborne fungal pathogens, Commun. Agric. Appl. Biol. Sci. 72(4), 2007, 785-793.

[37] J. Widelski, M. Popova, K. Graikou, K. Glowniak, I. Chinou, Coumarins from Angelica lucida L. - Antibacterial Activities, Molecules 14, 2009, 2729-2734.

[38] V. V. Makarov, A. J. Love, O. V. Sinitsyna, S. S. Makarova, I. V. Yaminsky, M. E. Taliansky, N. O. Kalinina, "Green" nanotechnologies: synthesis of metal nanoparticles using plants, Acta Naturae, 6(1), 2014, 35-44.

[39] B. G. Iversen, T. Jacobsen, H. M. Eriksen, G. Bukholm, K. K. Melby, K. Nygård, P. Aavitsland, An outbreak of Pseudomonas aeruginosa infection caused by contaminated mouth swabs. Clin Infect Dis. 44(6), 2007, 794-801.

[40] C. Kiffer, A. Hsiung, C. Oplustil, J. Sampaio, E. Sakagami, P. Turner, C. Mendes, Antimicrobial susceptibility of gram- negative bacteria in Brazilian hospitals: the MYSTYC Program Brazil 2003. Braz J Infect Dis. 9(3), 2005, 216-224.

[41] S. C. Ricke, Application of molecular approaches for understanding foodborne Salmonella establishment in poultry production. Adv Biol. 2014, 2014, 813275.

[42] R. Ramachandran, D. Sangeetha, Antibiofilm efficacy of silver nanoparticles against biofilm forming multidrug resistant clinical isolates, TPI, 6(11), 2017, 36-43.

[43] J. Wang, J. Li, G. Guo, Q. Wang, J. Tang, Y. Zhao, H. Qin, T. Wahafu, H. Shen, X. Liu, X. Zhang, Silver-nanoparticlesmodified biomaterial surface resistant to Staphylococcus: new insight into the antimicrobial action of silver, Sci Rep, 6, 2016, 32699-32714.

[44] C. H. N. Barros, G. C. F. Cruz, W. Mayrink, L. Tasic, Biobased synthesis of silver nanoparticles from orange waste: effects of distinct biomolecule coatings on size, morphology, and antimicrobial activity, Nanotechnol Sci Appl., 11, 2018, $1-14$.

[45] S. Basker, Synergistic efficacy of antibiotics and silver nanoparticles synthesized from Eichhornia crassipes, Research in Plant Biology, 6, 2016, 1-5.

[46] P. Tippayawat, N. Phromviyo, P. Boueroy, A. Chompoosor, Green synthesis of silver nanoparticles in aloe vera plant extract prepared by a hydrothermal method and their synergistic antibacterial activity, PeerJ, 4, 2016, e2589.

[47] J. K. Patra, K.-H. Baek, Antibacterial activity and synergistic antibacterial potential of biosynthesized silver nanoparticles against foodborne pathogenic bacteria along with its anticandidal and antioxidant effects, Front Microbiol., 8, 2017, 167. 